\title{
ACTUALITES CLINIQUES ET THERAPEUTIQUES SUR LES MALADIES SEXUELLEMENT TRANSMISSIBLES EN ANDROLOGIE
}

Les maladies sexuellement transmissibles sont des états pathologiques qui traversent les époques et ont toujours leur actualité. Aussi ce thème a été proposé pour la 2ème journée scientifique de la Société d'Andrologie de Langue Française et a permis d'explorer deux champs d'informations essentielles : les connaissances médicales les plus récentes et l'impact en terme de santé publique des M.S.T.

Le clinicien ne peut méconnaître l'évolution épidémiologique des M.S.T. avec le développement des agents pathogènes viraux et malgré une fréquence moindre, des agents bactériens. Cette modification de la présence des agents pathogènes confronte le praticien à de nouvelles thérapeutiques pour éviter ou améliorer une hypofertilité du couple et l'incite à réfléchir sur la prise en charge et les problèmes éthiques des procréations médicalement assistée face aux virus transmis sexuellement.

Cette 2ème journée scientifique de la SALF a permis de faire le point et d'évaluer les connaissances biologiques les plus récentes, permettant aux cliniciens de mieux cibler la recherche du germe pathogène et d'en évaluer les interactions sur la fertilité.

Le sujet toujours très controversé de la circoncision et des M.S.T. a a été également exposé lors de cette journée et a été, comme nous nous y attendions, très discuté.

L'exposé sur les infections virales transmises sexuellement a montré que les recherches cliniques et épidémiologiques sont encore nécessaires pour mieux comprendre par exemple l'évolution oncologique des papillomavirus humains chez l'homme, ou le risque de transmission de certains virus par le sperme. 